\title{
An experimental study of the behaviour of embedded lengths of cantilever walls
}

\author{
A. V. D. BICA and C. R. I. CLAYTON (1998). Géotechnique 48, No. 6, 731-745
}

\section{R. Phatak, B. B. Sonawane and H. B. Dhonde, Government Engineering College, Pune, India}

In connection with the evaluation of embedded length of cantilever walls, the authors have conducted interesting model tests. The discussers have found the embedded length of a cantilever wall for the same soil and wall conditions of the model test MT1 by different methods and compared them with the authors' experimental results, and the result are shown in Table 5 .

It thus appears that theoretical considerations to determine the critical depth of embedment for cantilever walls yield unrealistic and non-conservative results, and if these methods are employed for design purposes, a higher factor of safety should be employed.

\section{Authors' reply}

Phatak, Sonawane and Dhonde have calculated limit equilibrium depths of embedment for the MT1 model wall using several different analytical methods. The discussers conclude that these methods yield unrealistic and non-conservative results, and that they should only be used for design purposes in connection with higher factors of safety. Although recognising the significant drawbacks of the limit equilibrium approach, the authors do not agree with some of the discussers' conclusions. The four cases considered by the discussers are examined below.

\section{Case 1}

A free cantilever wall embedded in dense sand (corresponding to experiment MT1) shows a retained height at failure $h_{\mathrm{f}}=1.32 \mathrm{~m}$, angle of internal friction $\phi=47^{\circ}$, and angle of wall friction $\delta=\phi / 2=47^{\circ} / 2=23 \cdot 5^{\circ}$. The wall is vertical and the sand surface is horizontal. Earth pressure coefficients are evaluated from tables presented by Clayton et al. (1993), giving $K_{\text {ah }}=0.134$ (Mayniel) and $K_{\mathrm{ph}}=21.1$ (Caquot \& Kerisel). The requirement of moment equilibrium about the toe for a factor of safety equal to 1 gives a depth of embedment $d=0.30 \mathrm{~m}$. According to modern versions of Blum's method (see Clayton et al., 1993), the limit equilibrium depth of embedment required for satisfying both moment equilibrium and horizontal force equilibrium can be estimated as $d_{\mathrm{f}}=1.2 \times 0.30 \approx 0.36 \mathrm{~m}$. This corrected value is very similar to the experimental value $d_{\mathrm{f}}=0.35 \mathrm{~m}$. It appears that the value of depth of embedment required for moment equilibrium about the toe quoted by the discussers $(d \approx 0.30 \mathrm{~m})$ has not been corrected for the implicit neglect of horizontal force equilibrium. Without applying this correction, their value of $d \approx 0.30$ cannot be compared directly with the experimental value of $d_{\mathrm{f}}=0.35 \mathrm{~m}$.

\section{Case 2}

The same free cantilever wall of Case $1\left(h_{\mathrm{f}}=1.32 \mathrm{~m}\right.$, $\phi=47^{\circ}$ and $\delta=23 \cdot 5^{\circ}$ ) is considered. Earth pressure coefficients are evaluated with Coulomb's method, giving $K_{\text {ah }}=$ $0 \cdot 134$ and $K_{\mathrm{ph}}=26 \cdot 3$. The depth of embedment required for moment equilibrium about the toe is calculated as $d=0.275 \mathrm{~m}$ (similar to the discussers' value of $d=0.274 \mathrm{~m}$ ). Following Blum's method, the limit equilibrium depth of embedment required for both moment equilibrium and horizontal force equilibrium is calculated as $d_{\mathrm{f}}=1.2 \times 0.275 \approx 0.33 \mathrm{~m}$. This corrected value is slightly smaller than the experimental value $d_{\mathrm{f}}=0.35 \mathrm{~m}$. This is not surprising, as the assumption of rectilinear rupture surface characteristic of Coulomb's method implies that values of $K_{\mathrm{p}}$ are generally too high. As discussed by Clayton et al. (1993), Coulomb's values of $K_{\mathrm{p}}$ become nonconservative when $\delta>0$, and their use should be avoided. The Caquot \& Kerisel values of $K_{\mathrm{p}}$ should be used instead.

\section{Case 3}

The same free cantilever wall of Case $1\left(h_{\mathrm{f}}=1.32 \mathrm{~m}\right.$, $\phi=47^{\circ}$ and $\delta=23.5^{\circ}$ ) is considered, again with $K_{\text {ah }}=0.134$ (Coulomb) and $K_{\mathrm{ph}}=21.1$ (Caquot \& Kerisel). In this case, the earth pressure diagram shown in Fig. 1 of our paper (denoted as 'full method' by Padfield \& Mair, 1984) is considered. Both moment equilibrium and equilibrium of horizontal forces are then required, so that the limit equilibrium depth of embedment is directly calculated as $d_{\mathrm{f}}=0.31 \mathrm{~m}$. For this case, the position of the rotation centre of the wall is also determined (it is situated at a distance of $0.021 \mathrm{~m}$ above the wall toe). The calculated value of $d_{\mathrm{f}}=0.31 \mathrm{~m}$ is slightly larger than the discusser's quoted value of $d_{\mathrm{f}}=0 \cdot 30 \mathrm{~m}$. Both are smaller than the experimental value $d_{\mathrm{f}}=0.35 \mathrm{~m}$. However, this conclusion is again not surprising, because passive earth pressures on the retained side of the wall, below the rotation centre, were calculated assuming the same value of $K_{\mathrm{ph}}=21 \cdot 1$ as was considered in front of the wall, just below the excavation level. There is significant theoretical and experimental evidence (reviewed in our paper) that the value of $K_{\mathrm{ph}}$ to be considered near the wall toe must be much smaller than at the excavation level, owing to the downwards orientation of wall friction near the wall toe. Case 3 was therefore recalculated by the authors using a more realistic value of $K_{\mathrm{ph}}$ on the retained side of the

Table 5. Comparison of theoretical and experimental results

\begin{tabular}{c|l|c}
\hline Case No. & \multicolumn{1}{|c|}{ Method } & $\begin{array}{c}\text { Critical depth of } \\
\text { embedment: } \mathrm{m}\end{array}$ \\
\hline 1 & $\begin{array}{l}\text { Assuming rotation at toe point of wall and using Mayniel (1808) and Caquot \& Kerisel (1948) earth pressure } \\
\text { coefficients for active and passive earth pressures, as shown in Fig. 16. } \\
\text { Rotation at to point but using Coulomb's earth pressure coefficients for active and passive earth pressures, }\end{array}$ & $0 \cdot 30$ \\
2 & $\begin{array}{l}\text { as shown in Fig. 16. } \\
\text { Point of rotation above the toe of the wall and employing Mayniel and Caquot-Kerisel earth pressure } \\
\text { coefficients for active and passive earth pressures, as shown in Fig. 17. }\end{array}$ & $0 \cdot 27$ \\
4 & Bica \& Clayton (1991, 1998) by using experimental data; see Fig. 17. & $0 \cdot 30$ \\
\hline
\end{tabular}




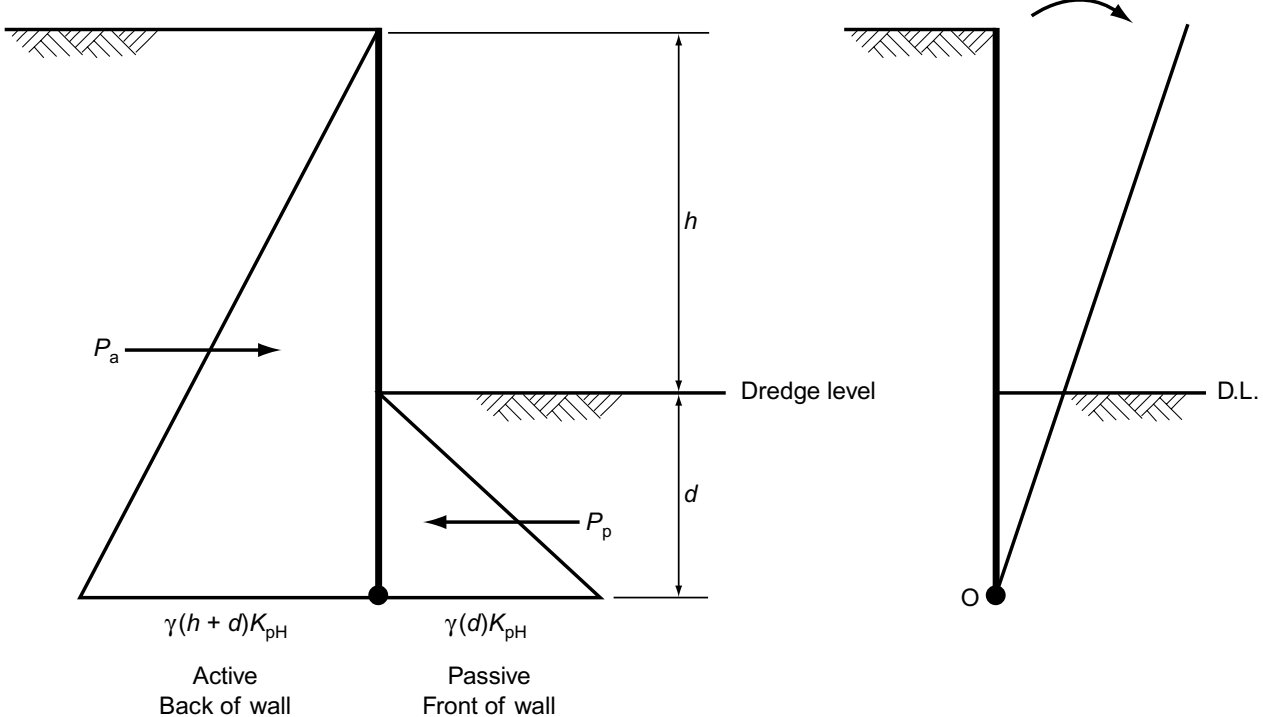

Fig. 16. Limit equilibrium analysis: distribution of earth pressure, rotation at toe point

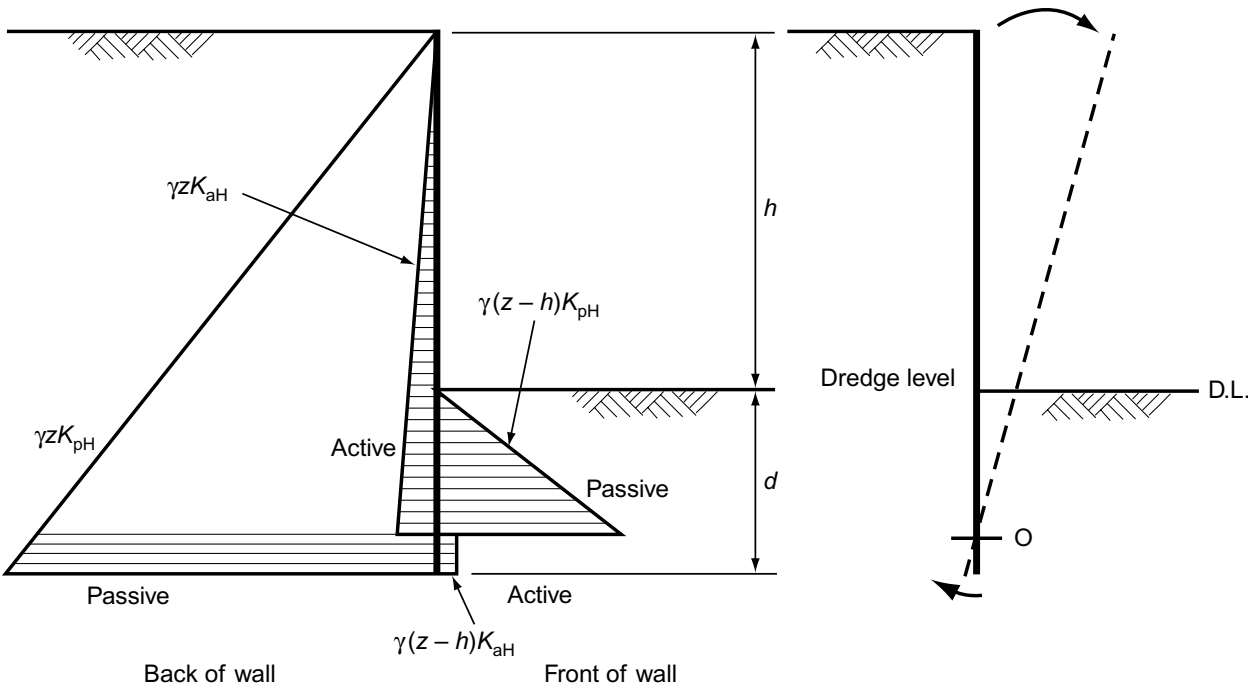

Fig. 17. Limit equilibrium analysis: distribution of earth pressure, rotation above toe point

wall, below the rotation centre. This value was determined with Coulomb's method, but considering wall friction acting downwards (for this case $K_{\mathrm{ph}}=2 \cdot 45$ ). A computed value of $d_{\mathrm{f}}=0.38 \mathrm{~m}$ was then obtained, with the rotation centre now situated at a distance of $0.13 \mathrm{~m}$ above the wall toe. This computed value of $d_{\mathrm{f}}$ is slightly larger than the experimental value of $d_{\mathrm{f}}=0.35 \mathrm{~m}$.

The authors therefore do not agree entirely with the discussers' conclusion that design methods for free embedded cantilever walls are unsafe. In the authors' opinion, current design methods can yield reasonable predictions of limit equilibrium depths of embedment $d_{\mathrm{f}}$ provided realistic assumptions are made with regard to the following issues:

(a) Values of $K_{\mathrm{p}}$ on the excavated side of the wall, above the rotation centre, must be determined with earth pressure theories that assume curvilinear rupture surfaces.

(b) When $d_{\mathrm{f}}$ is evaluated solely from moment equilibrium above the wall toe, a correction must be applied to the calculated depth of embedment to account for the neglected equilibrium of horizontal forces (this correction factor is not a safety factor).

(c) When $d_{\mathrm{f}}$ is evaluated from the requirement of both moment equilibrium and equilibrium of horizontal forces, a realistic (i.e. relatively small) value of $K_{\mathrm{p}}$ must be assumed on the retained side of the wall, below the rotation centre.

The main difficulty with the application of current design methods is instead the evaluation of the design depth of embedment. The accuracy and safety of this evaluation are still dependent on many other factors (some of them poorly known), as reviewed by Bica \& Clayton (1989) and Powrie (1996). It is not surprising that a number of alternative methods have been proposed for the design of free embedded cantilever walls during the past 15 years, including the use of empirical charts (Bica \& Clayton, 1992), finite elements analyses (Fourie \& Potts, 1989), and modified net-pressure limit equilibrium analyses (King, 1995; Day, 1999). This reflects the continuing research effort towards the improvement of retaining wall design methods.

\section{REFERENCES}

Bica, A. V. D. (1991). A study of free embedded cantilever walls in granular soil. $\mathrm{PhD}$ thesis, University of Surrey, Guildford, UK.

Bica, A. V. D. \& Clayton, C. R. I. (1989). Limit equilibrium design methods for free embedded cantilever walls in granular materials. Proc. Inst. Civ. Engrs, Part I 86, 879-989. 
Bica, A. V. D. \& Clayton, C. R. I. (1992). The preliminary design of free embedded cantilever walls in granular soil. In C. R. I. Clayton (ed.), Retaining structures, pp. 731-740. London: Thomas Telford.

Caquot, A. \& Kerisel, J. (1948). Tables for the calculation of passive pressure, active pressure and bearing capacity of foundations. Paris: Gauthier-Villars.

Clayton, C. R. I., Milititsky, J. \& Woods, R. I. (1993). Earth pressure and earth retaining structures, 2 nd edn. London: Blackie.

Day, R. A. (1999). Net pressure analysis of cantilever sheet pile walls. Géotechnique 49, No. 2, 231-245.
Fourie, A. B. \& Potts, D. M. (1989). Comparison of finite element and limit equilibrium analyses for an embedded cantilever retaining wall. Géotechnique 39, No. 2, 175-188.

King, G. J. W. (1995). Analysis of cantilever sheet-pile walls in cohesionless soil. J. Geotech. Engng, ASCE 121, No. 9, 629-635.

Mayniel, K. (1808) Traité experiméntal, analytique et practique de la pousseé des terres et des murs de revêtement, Paris

Padfield, C. J. \& Mair, R. J. (1984). Design of retaining walls embedded in stiff clays, Report 104. London: CIRIA.

Powrie, W. (1996). Limit equilibrium analysis of embedded retaining walls. Géotechnique 46, No. 4, 709-723. 